\section{THE COUNCIL FOR THE PROMOTION OF FIELD STUDIES}

\author{
By F. H. C. BUTLER \\ Honorary Secretary
}

$I^{\mathrm{N}}$ $\mathrm{N}$ all branches of knowledge which deal with the nature or configuration of the earth, or with its animal or plant population, or with human ecology, past and present, teaching cannot be adequate unless the student can learn in the field as well as in the lecture-room, library and laboratory; this is equally important whether he is to become a teacher, an administrator or a research worker. It is difficult, often impossible, to carry out adequate field excursions from school or university. The time taken in travelling to and from any but the nearest localities leaves little opportunity for serious work; the carriage of apparatus and equipment is also a major problem. Moreover, in research it is often necessary that continuous observations in the field should be carried out over long periods ; this is essential where the subject-matter of a problem is so great that its adequate investigation will take many years; for example, the detailed geological or geographical study of selected areas, or the study of fauna and flora. It is equally essential where seasonal changes are all-important, such as the effect of weather on coastal configuration, or the observation of seasonal changes in the fauna and flora of the sea, lakes and rivers, or on the land. A great deal of the biological field-work done at present loses much of its value because of the impossibility of making regular observations in the same area throughout the year.

In order to meet such difficulties on an adequate scale, the Council for the Promotion of Field Studies was founded in 1943; a report of the inaugural meeting was given in Nature of December 18 of that year. A leaflet was issued by the Council last June giving a brief description of its aims, membership, proposed constitution and current activities. In February this year the first number of the C.P.F.S. Bulletin was published. The aims of the Council are to provide facilities for every aspect of field-work at first-hand, and to set up for this purpose residential field study and research centres, distributed throughout Britain, in localities selected for the richness and variety of their ecological features, geological and geographical interest and archæological and historical importance. The field centres will be available alike to all serious workers in the field, whether amateur or professional, whether as individuals or as members of a class from a school, training college, university, young people's college, youth club, or other corporate body. The Council wishes to co-operate closely with local societies and field clubs, and through the centres -many of which will be situated in or near Nature reserves or national parks-should be able to play an important part in the training of the community in sound knowledge, $x$ sthetic appreciation and proper use of the countryside.

The Council is working in close co-operation with the National Trust, which is fully in sympathy with its proposals. It is hoped to establish the field centres so far as possible by leasing National Trust properties, care being taken in their adaptation and use to ensure their preservation as national monuments, while at the same time putting them to a cultural purpose. For the establishment of the first field centre, the
National Trust in 1943 made an offer to the Council of the lease of Flatford Mill and Willy Lott's Cottage in East Suffolk, made famous by Constable, and admirably suited to scientific and artistic studies. Prof. W. A. F. Balfour-Browne made a generous gift to cover the first year's rent, and application was made in June 1944 to the Carnegie United Kingdom Trust for a capital grant towards the considerable cost of adaptation and equipment. The Trustees expressed their interest in the aims of the Council and agreed to contribute up to $£ 2,000$ for this purpose. Negotiations with the National Trust for the lease of this property have therefore been concluded, and when labour and materials become available the work is to be carried out under the professional direction of Mr. Marshall Sisson, who has been appointed consulting architect to the Council. The family of the late Miss Alice HibbertWare has generously presented her unique collection of natural history material for the use of students at Flatford. It is hoped to dedicate the library to the memory of James Reid Moir, the well-known Ipswich field archæologist, who did so much of his scientific work in the neighbourhood and who lived in the Mill House for the last five years of his life; he greeted the foundation of the Council for the Promotion of Field Studies with enthusiasm and his help would have been invaluable.

It is the unanimous view of the Executive and General Committees of the Council that the success of its scheme depends on the possibility of establishing a number of field centres in different parts of Great Britain more or less simultaneously as soon as possible after the general conclusion of world hostilities, to be followed by others as occasion and opportunity offer. The general demand for propertics suitable for centres is rapidly increasing; for the Council's needs their precise location is of paramount importance on ecological grounds; it is therefore essential that the Council should be in a financial position to take urgent selective action before it is too late, as present opportunities are never likely to recur. Regional sub-committees covering England and Wales have been appointed to advise the Executive Committee on the selection of suitable sites, with the requisite accommodation for centres, in their areas. Mr. Hubert Smith, chief agent of the National Trust and a member of the Council's executive committee, is kindly advising the sub. committees when suitable Trust properties become available.

- In addition to the grant from the Carnegie Trust, the University of Cambridge, on the recommendation of three faculty boards (Biology 'A', Geography and Geology, Archæology and Anthropology) and the General Board of Studies, has agreed to put the capital sum of $£ 600$ at the disposal of the Council towards initial expenses incurred in establishing field centres. The University of Bristol and the University of Leeds have allocated token annual grants and a donation has been received from University College, Hull. Owing to the unique opportunities for teaching, study and research in the field that will be made available to them as the centres become established, the Council looks to each of the other universities for at least token financial support at the earliest possible moment. As the Council's work will involve the management and ownership of property, with gradually increasing financial responsibilities, the Executive Committee considers it essential that the Council should become incorporated under the Com- 
panies Act, 1929, and the necossary application is being made. Under the constitution, the General Committee of the Council will be the statutory body responsible for the formulation of policy, the direction of activities and the election of the executive. It is composed of representatives appointed by the universities, scientific societies and institutions, leading organizations of the teaching profession and the main groups of natural history societies, field and art clubs. The Council's work will embrace very wide and varied interests, and, in order to be fully representative, the General Committee must necessarily be a large and influential body ; it is clear that finality in the election of official representatives cannot be reached until the Council gets into its stride, and it is important that this should be borne in mind. It is proposed that one quarter of the General Committee should be representatives of individual members.

At the first meeting of the General Committee held in the Royal Society's meeting room on April 25 the following resolutions were passed unanimously:

(1) This representative meeting strongly urges the great potential value of the work of the Council and the scientific, educational and cultural importance of taking immediate measures to establish a number of field centres actively in operation in different parts of the country.

(2) That the Executive Committee be instructed to take immediate measures to put this view before appropriate Government Departments, the Carnegie Trust and other bodies, with a view to securing a direct grant from the Treasury, and any other assistance which offers means of realizing the early fulfilment of our programme.

In some respects, the Council for the Promotion of Field Studies will perform for the culture of the countryside what the Council for the Encouragement of Music and the Arts has been doing for the presentation of music and the arts to the community. Not only will it introduce the serious first-hand study of the countryside to a new and to a much wider public, but also "the Council will," in the words of Prof. F. T. Brooks of Cambridge, "fill a very important gap in our system of education, both at the school and university level". Its functions are concerned with the processes and not merely with the products of intellectual achievement. It will play a vital part in many branches of research. Its financial needs are therefore no less great than those of C.E.M.A., and worthy of at least equal consideration for a direct annual Treasury grant.

The field centres will be staffed and equipped to provide adequate board, lodging and working facilities for numbers ranging up to forty or fifty students. They must cater for a wide variety of needs and interests-for 'every science and art the natural province of which is (or ought to be) the open air. They must be able to provide ample and varied material for study; attractive and comfortable but not extravagant living accommodation; the right tools and books and elbow-room during working hours; congenial and useful occupation in spare time. In function, they may be fairly described as residential university outposts in the field, for they would be field extensions of the departments of botany, zoology, geography, geology and archæology, and of essential use to students of history, dialect, place-names, folk-lore, anthropology, antiquities, art, agriculture, forestry, architecture, town and country planning, rural crafts, economics, sociology, and so forth. As it gradually becomes fully equipped, a field centre must combine adequate facilities for field work with some at least of the social amenities of a residential college. A field centre would, in short, offer its students something far more tangible, more lasting, than the limited experience of the 'day' excursion' or of the 'bench-experiment' kind.

Each centre will be under the direction of a trained warden. Although it is intended that classes of school and university pupils shall be accompanied by their own teachers, it is essential that the wardens of the field centres should be experienced naturalists and trained field-workers with wide cultural sympathies; they must be able to undertake specific instruction in the field in their own subject as well as advise on other activities in which an intimate general knowledge of the district will be necessary. The position of warden will be one of peculiar responsibility - he will have to direct, advise and collaborate in every way possible-and obviously on him will depend to a very large extent the success and efficiency of a centre. It is considered, therefore, that the post should carry with it a status comparable to that of a university reader or professor.

As well as the student and professional research worker, the Council is espocially anxious to attract and help the amateur-the 'born' naturalist, artist or archæologist-and hopes that local societies and field clubs will co-operate closely with the work of the centres. At each centre there must be, for the novice, expert help and individual encouragement; for the advanced student, every facility for research-the standard must be high in personnel and equipment. For professional research workers from institutions liko Wray Castle and Rothamsted, there must be facilities for obtaining comparative data in fundamental longterm investigations; each centre should be an ecological research station and have places reserved for investigators who wish to stay for long periods.

We have mentioned that the centres could be regarded as field outposts of various departments of a university. An important point is the co-operation which could be instituted at a centre between the work of different departments even of the same university. At present these function independently, but all would gain greatly if combined work were done. For example, biologists and archxologists would have the advantage of information about the geological formation of the area, for the maps and surveys of the geographers would be of service to them, while both geologists and geographers would benefit from first-hand information concerning the fauna and flora. Geologists could receive instruction from geographers in the methods of trigonometrical survey and tachyometry. Also, meteorological data and climatic (or micro-climatic) investigations would be fundamental to many studies. Thus students in different subjects would have the great advantage of working together, seeing each other's methods and results and learning, at first-hand, of the unity of knowledge, which is an ideal so difficult to attain within the somewhat water-tight compartments of a university. There would be further and wider advantages both of a social and cultural nature. Members of the staff as well as students of one university would meet those of other universities in their own as well as in other subjects, when staying at the same centre together. Furthermore, the association of art and science, under the informal and fortuitous circumstances in which their practi- 
tioners would meet, would at least be interesting and might well be beneficial to both.

For secondary schools, the centres would afford admirable opportunities for individual or group work in many subjects, including natural history, biology, geology, geography, history, art and allied studies. Many school syllabuses in biology-largely dictated by external examinations - are too academic to appeal to the average boy and girl, and are, therefore, not of the real educational value that they should be. Children are interested in studying living plants and animals in their natural environment, and it is coming to be realized among educationists that this aspect of the subject needs to be greatly encouraged; but unfortunately, few teachers-including university graduates in the biological sciences-have the requisite first-hand knowledge and experience of field-work to teach natural history with competence and enthusiasm. In biology (a subject which purports to be the science of living things), it is far easier to teach and examine classes of pupils by anatomizing dead specimens in the laboratory than by observing living organisms in the field, and this may account for the comparative neglect of the study of animals and plants in their natural habitats.

The evacuation scheme, whereby the schools were dispersed from the cities of Britain into the country. side during the War, has shown only too clearly that for many teachers the countryside is a closed book; comparatively few seem to have been able to make use of the excellent opportunities presented to them for first-hand observation and teaching in the field, even when there was no external examination syllabus to tie them down to an unadventurous and monotonous urban class-room routine. Moreover, in schools permanently situated in the country, it is the exception rather than the rule to do any serious work in the field in school hours, in studies (other than gardening) which specially lend themselves to observational work and the testing and illustrating of teaching and text-book authority at first hand. Admittedly, this work requires detailed knowledge and a carefully planned technique, which are at present outside the range of experience of many teachers in the schools, not having been demanded in their university studies or dealt with in their courses of professional training. The centres will be equipped and organized to enable this special knowledge of field-work to be acquired by teachers and pupils in the various subjects; also teachers will be able to learn the technique of handling classes in the field, which undoubtedly requires special training, experience and facilities, if the work is to be efficient and time and energy conserved. In course of time, perhaps, when the centres have become widely established, new influences will be brought to bear on school and university teaching and examining, and then the Council for the Promotion of Field Studies will be "filling the very important gap which exists in our system of education both at the school and university level'. It is hoped that the centres will be widely used by teachers and pupils in the schools, and that they will enjoy working out the fresh approach to culture that field-studies will bring them, with new kinds of technique, in places of great natural beauty that should rejoice the hearts of artists and craftsmen, as well as scientific men, geographers and historians.

Finally, the Council for the Promotion of Field Studies is a seientific society, and therefore it is important that the spirit of research should not be confined to field and laboratory, but should be applied to the planning, organization and equipment of the centres, and, indeod, to the general administra. tion of the Council's activities as a whole. What these activities will be in their completeness it is not yet possible to forecast; but from the widespread and eminent support that the Council has already recoived, it would seem that we are on the fringe of great possibilities of service to those who wish to make a first-hand study of the many branches of knowledge that have their source and inspiration in the field.

\section{THE SEVERN BARRAGE SCHEME}

COAL supplies in Great Britain having become 1 deficient in quantity and quality, public attention has been forcibly directed towards alternative sources of power and energy. The most novel and also the largest single source which has attracted public interest is the Severn Barrage. A scheme formulated by Mr. A. G. Vaughan-Lee, Sir William Halcrow and Mr. S. B. Donkin, published by the Ministry of Fuel and Power*, gives a broad outline of a method of utilizing tidal power in the Severn Estuary, provides an estimate of the amount of power and energy which would be made available, and the cost thereof.

The principle of the scheme is simple. A dam across the Severn enables water to be impounded on rising tides. This water flows through turbines on the succeeding falling tides. Its potential energy is converted to kinetic energy by the turbines and then to electrical energy by alternators directly coupled to these turbines.

The proposed dam is located at the English Stones, some two and a half miles downstream from the mouth of the River Wye, a rough locating point on the north bank of the Severn being the village of Snabrook. It is about two miles long, and comprises sections for inlet sluices, navigation locks and turbines. Thirty-two turbines, in two equal groups, would drive thirty-two alternators, each rated 25 MW. at 0.9 power factor. These would be capable of providing a maximum power output of $800 \mathrm{MW}$. At spring tide, when the power available is greatest, the total output from the alternators would rise to a maximum of $800 \mathrm{MW}$. in two and a half hours, remain at this value for four hours, and then fall to zero in a further period of about one hour. There would thus be two periods of about seven hours during each twenty-four, in which the plant would be able to generate power and energy. The maximum power and the hour at which it is available changes day by day in accordance with the state of the tide. These daily and seasonal changes of the power and energy output are to be balanced by suitable operation of the barrage power in conjunction with the electricity grid system of Britain.

The gross energy available at the barrage would be 2,365 million $\mathrm{kWh}$. per annum. If the water flow through the turbines were continuous, the energy available per annum would be 7,008 million $\mathrm{kWh}$. The ratio $\frac{2,365}{7,008}$, that is, $0 \cdot 47$, is important when

* Ministry of Fuel and Power. Report of the Severn Barrage Scheme. By A. G. Vaughan-Lee, Sir William Halcrow and S. B. Donkin. Pp.
32. (London: H.M. Stationery Office, 1945.) 28. 6d. net. 